\title{
Phytochemical Screening of Various Extracts of Root of Withania Somnifera (L) Dunal
}

\author{
Vinotha S \\ Unit of Siddha Medicine, University of Jaffna, Sri Lanka \\ Thabrew I \\ Institute of Biochemistry, Molecular Biology and Bio technology \\ University of Colombo, Sri Lanka \\ Sri Ranjani S \\ Unit of Siddha Medicine, University of Jaffna, Sri Lanka
}

\begin{abstract}
Withania somnifera (L) Dunal (Solanaceae), commonly known as Aswagandha, is one of the most valued medicinal plants with a number of pharmaceutical applications. The roots are the main portion of the plant used in herbal medicine. Root extracts of $W$. somnifera are commonly used as a remedy for variety of ailments and a general tonic for over all health and longevity in the Traditional medicine system. The aim of the study was to investigate the secondary metabolites of various extracts of root of $W$. somnifera and quantification of some of the active constituents like alkaloids, flavonoids, saponins and volatile oil according to standard procedures. The preliminary phytochemical screening of cold and hot ethanol, methanol and aqueous extracts showed the presence of alkaloids, saponins, flavonoids, steroids, tannins, proteins, reducing sugar and coumarins and absence of quinones or anthraquinones. The total alkaloid, flavonoid contents were found to be $0.81 \pm$ $0.01 \%, 14.43 \pm 0.40 \%$ and total saponin content was (Foaming Index) FI $<100$ respectively. The considerable amount of volatile oil was not determined in fresh root of $W$. somnifera. The findings are consistent with the presence of biologically active constituents in the polar extracts of $W$. somnifera and may provide helpful in authentication and identification of this plant.
\end{abstract}

Keywords: Different extracts, phytochemical screening, root, Withania somnifera

\section{INTRODUCTION}

Medicinal herbs are making a tremendous revival all over the globe. The herbal products today symbolize safety in contrast to the synthetics that are regarded as unsafe to human and environment. Over three quarters of the world population relies mainly on plants and plants extracts for health care (Lakshmi et al., 2011). In the Traditional system of medicine, which dates back many centuries, uses many herbal extracts to cure a variety of diseases including carcinoma (Singh et al., 2005). One such popularly used plant that is reported to have antiinflammatory, anti arthritic, antitumor, antioxidant, immunomodulatory, and hepatoprotective effects is Withania somnifera Dunal, which is commonly known as 'Ashwagandha' (Al-Hindawi et al., 1989; Mohammed et al., 1996; Rasool et al., 2000, Marie Winters, 2004; Subramanian et al., 2008 and Bhattacharya et al., 2008). It is useful in stress, strain, fatigue, pain, skin disease, diabetes, gastro intestinal disease, rheumatoid arthritis, and epilepsy (Kirtikar \& Basu, 1935; 
Nadharni, 2002 \& Sandhu et al., 2010). Due to its wide therapeutic importance it is worthwhile to obtain various qualitative and quantitative standards of drug to prevent its adulteration.

Although the phytochemical screening of this plant already published, this study is presented to compare on its phytochemical constituents in various extracts, which were performed by different extraction methods. Quantification of some of the active constituents like alkaloids, flavonoids, saponins and volatile oil were also carried out according to standard procedures. Thus, the present study deals with investigate the secondary metabolites of various extracts of root of W. somnifera.

\section{MATERIALS AND METHODS}

Plant materials and Chemicals: W. somnifera roots were purchased from a reputed vendor of herbal material (M. S. Marunthakam) in Jaffna District. The botanical identity of the plant was confirmed by the Botanist at Bandaranayaka, Memorial Ayurvedic Research Institute (BMARI), Navinna, Maharagma, Sri Lanka (Voucher specimen No. 2553).

All the reagents and chemicals used were procured from Institute of Industrial Technology \{ITI $\}$, Colombo- 07 and of analytical grade.

Preparation of Test material: The purchased W. somnifera roots were cut in to small pieces and gently boiled with cow's milk (1:1) for purification. These roots were air-dried thoroughly under shade (at room temperature) for 2-3 weeks to avoid direct loss of phytoconstituents from sunlight. The shade dried materials were powdered using the pulverizer and sieved up to 80 meshes. It was then homogenized to fine powder and stored in air-tight bottle for future use.

Preparation of the plant extracts: Hot extraction: A total of $10 \mathrm{gm}$ of powdered sample was taken and mixed with $50 \mathrm{ml}$ distilled water in a round bottom flask and gentle refluxed for $11 / 2$ hour separately. The residue was removed by filtration through Whatmann No:1 filter paper and the aqueous extract was concentrated used on a Rotary evaporator (Buchi) for just as long as was required to remove the solvent, and re-dissolved the residue in a small volume (2 or 3 $\mathrm{ml}$ ) of water.

Cold extraction: A total of $10 \mathrm{gm}$ of powdered sample was successively extracted with $50 \mathrm{ml}$ distilled water and stirred magnetically (Magnetic stirrer- Snijders) in a container for 11/2 hour at room temperature. The extract was filtered through filter paper and concentrated by a Rotary evaporator for just as long as was required to remove the solvent, and re-dissolved the residue in a small volume ( 2 or $3 \mathrm{ml}$ ) of water (Thirumalai et al., 2011).

Finally, the all extracts were collected in clean stoppered glass test tubes separately and used for phytochemical screening.

Same procedures were followed using ethanol and methanol instead of distilled water to prepare the cold and hot ethanol and methanol extracts.

Organoleptic Characters: The organoleptic characters of plant base products are evaluating the qualities of preparation by color, touch, fineness, taste, odor, etc. were noted through sense organs and it is providing the idea about the quality of different formulations without using chemical tests. Organoleptic characters of the root of W. somnifera crude powder, and it's 
aqueous and alcoholic extracts were evaluated based on the method described by Siddiqui et al., 1995.

Preliminary Phytochemical Screening: The preliminary phytochemical screening of the various (cold \& hot ethanol; methanol and water) extracts of root powder of W. somnifera were carried out according to standard laboratory procedures, to detect the presence of different secondary metabolites such as alkaloids, flavonoids, saponins, tannins, steroid glycosides, phenols, coumarins, reducing sugars, protein, anthraquinones, quinines, fat and fixed oil (Kokate et al. 1995; Farnsworth, 1996; Gupta et al. 2008; Prashant Tiwari et al. 2011 and Saxena et al., 2012).

Quantitative Estimations: Estimation of Total Alkaloid: Quantitatively, alkaloid was determined using the procedure forward by Harborne, 1973; as described by Edeoga et al., 2005 and Aliyu et al., 2008.

Briefly, five grams (5 g) of root powder was weighed into $250 \mathrm{ml}$ beaker and $200 \mathrm{ml}$ of $20 \%$ acetic acid was added and covered to stand for $4 \mathrm{hr}$. This was filtered and the extract was concentrated using a water bath to one quarter of the original volume. Concentrated ammonium hydroxide was added drop wise to the extract until the precipitate was complete. The whole solution was allowed to settle and the precipitate was collected by filtration through the accurately weighed filter paper. The residue is the alkaloid, which was dried at oven for 4 hours and weighed. Total alkaloid content was calculated as mg per g of air-dried material.

Estimation of Total Flavonoids: Flavonoids were determined using the procedure forward by Boham and Kocipaiabyazan (1994) as described by Edeoga et al., 2005 and Aliyu et al., 2008.

Briefly, $10 \mathrm{~g}$ of the root powder was extracted repeatedly with $100 \mathrm{ml}$ of $80 \%$ aqueous methanol at room temperature. The whole solution was then filtered using Whatman No:42 $(125 \mathrm{~mm})$ filter paper. The filtrate was later transferred into accurately weighed crucible and evaporated to dryness over a water bath and weighed to a constant weight. The weight is flavonoids. Total flavonoid content was calculated as mg per g of air-dried material.

Estimation of Total saponin (Determination of foaming index): Many medicinal plant materials contain saponins that can cause persistent foam when an aqueous decoction is shaken. The foaming ability of an aqueous decoction of plant materials and their extracts is measured in terms of a foaming index. Saponins were determined according to the method described by World Health Organization (WHO, 1998).

About $1 \mathrm{~g}$ of the root powder weighed accurately and transferred to a $500 \mathrm{ml}$ conical flask containing $100 \mathrm{ml}$ of boiling water. Maintain at moderate boiling for 30 minutes. Cooled and filtered into a $100 \mathrm{ml}$ volumetric flask and added sufficient water through the filter to dilute to volume. Poured the decoction into 10 stopper test-tubes (height $15 \mathrm{~cm}$, diameter $15 \mathrm{~mm}$ ) in series of successive portions of $1 \mathrm{ml}, 2 \mathrm{ml}, 3 \mathrm{ml}$, up to $10 \mathrm{ml}$ and the volumes in each tube adjusted with water to $10 \mathrm{ml}$. Stoppered the tubes and shaken them in a lengthwise motion for 15 seconds, two shakes per second. After allowed the tubes to stand for 15 minutes and the height of the foam was measured by means of a graduated tape with millimetre scale.

Determination of volatile oil: Fresh roots of W. somnifera were washed to remove dirt, chopped into small pieces and ground in a blender. The material was subjected to hydro distillation using Clavenger-type glass apparatus for 4 hours separately. Then, observation done whether the volatile oil present or absent (WHO, 1998 \& Hina Fazal et al. 2011). 
Table 1: Organoleptic characters of crude powder, aqueous and ethanolic extracts of the Root of W. somnifera

\begin{tabular}{lllll}
\hline $\begin{array}{l}\text { Name of the crude powder \& } \\
\text { extracts }\end{array}$ & Appearance & Colour & Taste & Odour \\
\hline $\begin{array}{l}\text { 1. Crude powder } \\
\begin{array}{l}\text { 2. Aqueous extracts- } \\
\text { Cold water extract }\end{array}\end{array}$ & Powder & Whitish brown & Bitter & Characteristic \\
$\begin{array}{l}\text { Hot water extract } \\
\text { 3. Alcoholic extracts- }\end{array}$ & Liquid & Light brown & Bitter & Characteristic \\
Cold ethanol extract & Liquid & Brown & Bitter & Characteristic \\
Hot ethanol extract & Liquid & Orange & Bitter & Characteristic \\
Cold methanol extract & Liquid & Dark yellow & Bitter & Characteristic \\
Hot methanol extract & Liquid & Orange & Bitter & Characteristic \\
\hline
\end{tabular}

Statistical analysis: Statistical analysis of the results obtained in quantitative estimation was carried out by use of the Ms Excel 2007 statistical software and mean values along with standard deviation were recorded.

\section{OBSERVATION AND RESULTS}

The Organoleptic characters of aqueous and alcoholic extract of the root of W. somnifera, are tabulated as Table 1. The phytochemical active compounds of various extracts of root of $\mathrm{W}$. somnifera were qualitatively analyzed and the results are presented in Table 2 . The quantitative test for various functional groups is tabulated as Table 3.

Table 2: Phytocochemical Screening of various (cold \& hot aqueous and alcohol) extracts of root of W. somnifera

\begin{tabular}{|c|c|c|c|c|c|c|}
\hline \multirow[b]{2}{*}{ Components } & \multicolumn{6}{|c|}{ Various Extracts } \\
\hline & $\begin{array}{l}\text { Cold } \\
\text { Ethanol }\end{array}$ & $\begin{array}{l}\text { Hot } \\
\text { Ethanol }\end{array}$ & $\begin{array}{l}\text { Cold } \\
\text { Methanol }\end{array}$ & $\begin{array}{l}\text { Hot } \\
\text { Methanol }\end{array}$ & $\begin{array}{l}\text { Cold } \\
\text { Aqueous }\end{array}$ & $\begin{array}{l}\text { Hot } \\
\text { Aqueou } \\
\text { S }\end{array}$ \\
\hline $\begin{array}{l}\text { Phenolic compound } \\
\text { Flavonoids- }\end{array}$ & +++ & +++ & +++ & +++ & +++ & +++ \\
\hline Shinoda test & +++ & +++ & +++ & +++ & + & + \\
\hline Coumarins & +++ & +++ & +++ & +++ & +++ & +++ \\
\hline Quinones & 0 & 0 & 0 & 0 & 0 & 0 \\
\hline Anthraquinones & 0 & 0 & 0 & 0 & 0 & 0 \\
\hline Tannins- & & & & & & \\
\hline $\begin{array}{l}\text { Ferric chloride test } \\
\text { Saponins- }\end{array}$ & +++ & +++ & +++ & +++ & +++ & +++ \\
\hline $\begin{array}{l}\text { Foam test } \\
\text { Protein- }\end{array}$ & ++ & ++ & ++ & ++ & + & + \\
\hline $\begin{array}{l}\text { Xanthoproteic Test } \\
\text { Steroid-glycosides- }\end{array}$ & ++ & ++ & ++ & ++ & ++ & ++ \\
\hline $\begin{array}{l}\text { Libermann Burchard's test } \\
\text { Alkaloids }\end{array}$ & +++ & +++ & +++ & +++ & ++ & ++ \\
\hline Mayer's Test & +++ & +++ & +++ & +++ & +++ & +++ \\
\hline $\begin{array}{l}\text { Dragendroff's Test } \\
\text { Reducing sugars- }\end{array}$ & +++ & +++ & +++ & +++ & +++ & +++ \\
\hline Fehling's test & +++ & +++ & +++ & +++ & +++ & +++ \\
\hline Fixed oil and Fats & 0 & 0 & 0 & 0 & ++ & ++ \\
\hline
\end{tabular}


$+++=$ appreciable amount, $++=$ average amount, $+=$ trace amount, $\mathbf{0}=$ absent

Table 3: Total alkaloids, flavonoid and saponin contents in root powder of root of $W$. somnifera

\begin{tabular}{llcl} 
Name of the plant material & Total alkaloids & Total flavonoids & $\begin{array}{l}\text { Total saponins (Foaming } \\
\text { Index) }\end{array}$ \\
\hline
\end{tabular}

Root powder of $\quad$ W. $0.81 \pm 0.01 \quad 14.43 \pm 0.40 \quad$ FI $<100$

somnifera

Values are expressed as mean $\% \pm$ S.D., $\mathrm{n}=3$

\section{DISCUSSION}

Secondary metabolites were found in good proportion in alcoholic and aqueous extracts when compared. These secondary metabolites may be responsible for various pharmacological effects of ethanolic, methanolic and aqueous extracts of preparations. Such preliminary phytochemical screening was helpful in prediction of nature of drugs and also useful for the detection of different of different constituents present in different polarity solvent.

So it could be helpful to extract out particular constituents by solvent (Shwetajain, et al., 2011).

The secondary metabolites such as alkaloids, flavonoids, lignins, terpenoids, steroids, glycosides, coumarins and phenols in plant materials produce the curative effect when they are used in the traditional medical practice (Sane et al., 1997).

As seen in Table 1, both the aqueous and alcoholic extracts of Root powder of W. somnifera had similar organoleptic properties except for the colour of the each extracts. In analysis of Tannin compounds brownish green colour developed to indicate the presence of Tannin. Similarly based on the presence or absence of colour change indicate positive and negative results. In these screening process alkaloids, saponins, flavonoids, steroids, tannins, coumarins, phenols, proteins, reducing sugars, fixed oil and fats gave positive results and anthraquinones and quinones gave negative results for cold and hot ethanol, methanol and water extracts of root powder of W. somnifera. Cold and hot water extracts showed the presence of fats and fixed oil. Higher flavonoids, steroidal glycosides and saponins content were found in the cold and hot ethanol and methanol extracts than in the cold and hot water extracts of root of W. somnifera.

Earlier studies for phytochemical screening that presence of alkaloids, flavonoids, steroids, tannins, terpenoids, saponins and sugars in alcoholic root extract (Brijendra et al., 2010); presence of alkaloids, flavonoids, saponins, steroids, and tannins in crude extract of W. somnifera (Khan et al., 2010; Mukesh \& Smita 2010) presence of alkaloids, flavonoids, tannins, saponins, glycosides, phenols, protein, phytosterol, triterpenoids and reducing sugars in ethanolic root extract (Bimlesh Kumar et al., 2011) and presence of terpenoids, alkaloids, saponins, carbohydrates, glycosides, flavonoids, tannins and steroids in Hydromethanolic root extract (Nasreen \& Radha 2011)

As seen in Table 3, the total alkaloid (20\% acetic acid extract) and flavonoid ( $80 \%$ of aqueous methanol extract) contents were found to be $0.81 \pm 0.01 \%$ and $14.43 \pm 0.40 \%$ respectively and total saponin (hot water extract) content was (Foaming Index) FI $<100$. The considerable amount of volatile oil was not determined in fresh root of W. somnifera. 
Previous study stated that, the total alkaloid content was found to be $0.9818 \mathrm{mg} / 100 \mathrm{~g}$ of root powder of W. somnifera (Nasreen \& Radha 2011).

\section{CONCLUSION}

The present study has revealed the presence of many secondary metabolites in the various extracts of root of W. somnifera powdered preparation. It has the further confirmed that these plant extracts could be used for the treatment of various ailments. The findings are consistent with the presence of biologically active constituents in the polar extracts of W. somnifera and may provide helpful in authentication and identification of this plant.

\section{ACKNOWLEDGMENT}

The financial support provided Higher Education Twenty first Century (HETC) Project, Ministry of Higher Education, Sri Lanka, and the assistance given by Dr. (Mrs) Menuka Arawwawala, Industrial Technology Institute (ITI), Colombo, to conduct the phytochemical analysis are gratefully acknowledged.

\section{References}

1. Al-Hindawi MK, Al-Deen IH, Nabi MH, Ismail MA. Anti-inflammatory activity of some Iraqi plants using intact rats. J Ethnopharmacol. 1989 Sep; 26(2):163-8.

2. Aliyu AB, Musa AM, Oshanimi JA, Ibrahim HA and Oyewale AO. Phytochemical analysis and Mineral elements composition of some Medicinal plants of Northern Nigeria. Nigerian Journal of Pharmaceutical Sciences, March, 2008, Vol. 7 (1):119- 125.

3. Bhattacharya SK, Bhattacharya D, Sairam K, Ghosal S. Effect of Withania somnifera glycowithanolides on a rat model of tardive dyskinesia. Phytomedicine, 2002; Volume 9(2); 167-170.

4. Bimlesh Kumar, Shakti Puri, Jiban Debnath, Prashant Tiwari, Manoj Salhan, Mohanjit kaur, Amit Mittal. Comparative pharmacological evaluation of adaptogenic activity of Holoptelea integrifolia and Withania somnifera. Int. J. Drug Dev. \& Res., Jan-March 2011, 3(1): 84-98.

5. Brijendra Kr. Singh, Rajat Gahoi and Anuj Sonkar. Quality assessment and phytochemical screening of selected region of Withania somnifera Dunal. International Journal Pharmaceutical Sciences Research, 2010; Vol. 1(7): 73-77.

6. Edeoga, HO, Okwu DE, Mbaebie BO. Phytochemical constituents of some Nigerian medicinal plants. African Journal of Biotechnology, July 2005; Vol. 4 (7): 685-688.

7. Farnsworth NR. Biological and Phytochemical screening of Plants. Journal of pharmaceutical Science, Vol. $55,1996,225-276$.

8. Gupta AK, Neeraj Tandon, Madhub Sharma. Quality Standards of Indian Medicinal Plants. Indian Council of Medical Research, New Delhi, Vol. 7, 2008, 331-339.

9. Hina Fazal, Nisar Ahmad and Mir Ajab khan. Physico-chemical, Phytochemical Evaluation and DPPHScavenging Antioxidant potential in Medicinal Plants used for herbal formulation in Pakistan. Pak. J. Bot., 2011, Special Issue 43: 63-67.

10. Khan ZS, and Nasreen S. Phytochemical analysis, antifungal activity and mode of action of methanol extracts from plants against pathogens. Journal of Agricultural Technology, 2010; Vol. 6(4): 793-805.

11. Kirtikar KR and Basu BD. Indian Medicinal plants. 2nd ed., Vol. 1- 4; 1935, Reprint. Delhi: Periodical Experts. 1993.

12. Kokate CK, Khandelwal KR, Pawer AP \& Gokhale SB. Practical Pharmacognosy. 3rd edition, Nirali Prakashan, Pune, 1995, 137.

13. Lakshmi PTV, Annamalai A, and Ramya C. A study on the Genetic Diversity Analysis of a medicinally potential herb- Enicostemma littorale Biume (Gentianaceae). International Journal of Pharma and Bio Sciences, Oct-Dec 2011; Vol. 2(4): 238-445. 
14. Marie Winters ND. Ancient Medicine, Modern Use: Withania somnifera and its Potential Role in Integrative Oncology. Alternative Medicine Review, 2004; Volume 11, Number 4: 269-277.

15. Mohammed Ziauddin, Neeta Phansalkar, Pralhad Patki, Sham Diwanay, Bhushan Patwardhan. Studies on the immunomodulatory effects of Ashwagandha. Journal of Ethnopharmacology, 1996; 50: 69-76.

16. Mukesh Chandra Sharma and Smita Sharma. Phytochemical, Preliminary Pharmacognostical and Antimicrobial Evaluation of Combined Crude Aqueous Extract. International Journal of Microbiological Research, 2010; 1(3): 166-170.

17. Nadharni K, Indian Materia Medica, Vol. I, Vegetable kingdom, Bombay Popular Prakashan, 2002, 485, 1292-1294.

18. Nasreen S \& Radha R. Assessment of Quality of Withania somnifera Dunal (Solanaceae) Pharmacognostical and physicochemical profile. International Journal of Pharmacy and Pharmaceutical Sciences, 2011, vol. 3. No. 2, 152-155.

19. Organization Mondiale De La Sante. Quality control methods for plant materials. 559, Rev.1, Original English, World Health Organization; 1998, 8-67.

20. Prashant Tiwari, Bimlesh Kumar, Mandeep Kaur, Gurpreet Kaur \& Harleen Kaur. Phytochemical screening and Extraction: A Review. Internationale Pharmaceutica Sciencia, Vol. 1, Issue 1, 2011, 98-106.

21. Rasool M, Latha LM and Varalakshmi P. Effect of Withania somnifera on Lysosomal Acid Hydrolases in Adjuvant-induced Arthritis in Rats. Pharmacy and Pharmacology Communications, 2000; 6: 187-190.

22. Sandhu JS, Biren Shah, Shweta Shenoy, Suresh Chauhan, Lavekar GS, Padhi MM. Effects of Withania somnifera (Ashwagandha) and Terminalia arjuna (Arjuna) on physical performance and cardiorespiratory endurance in healthy young adults, International Journal of Ayurveda Research, JulySeptember 2010, Vol. 1(3): 144-149.

23. Sane RT, Chawla JL, and Kuber VV, Indian Drugs, 1997, 34; 580-584.

24. Saxena N, Shrivastava PN \& Saxena RC. Preliminary Physico-Phytochemical Study of stembark of Alstonia scholaris (L) R. BR. - A Medicinal Plant. IJPSR, Vol. 3(4): 2012, 1071-1075.

25. Shwetajain, Chanderachud Sharma, Pankaj Khatri, Atul Jain, Ankur Vaidya. Pharmacognostic and Phyto chemical Investigations of the Leaves of Zizyphus xylopyrus (Retz) Willd. International Journal of Pharmacy and Pharmaceutical Sciences, Vol 3(2): 2011; 122-125.

26. Siddiqui \& Hakim MA. Format for the pharmacopoeial analytical standards of compound formulation. Workshop on standardization of Unani drugs, anuary, Central Council for Research in Unani Medicine (CCRUM), New Delhi, (appendix) 1995, 24-25.

27. Singh RP, Padmavathi B, Rathb PC \& Rao AR. Roots of Withania somnifera Inhibit Fore stomach and Skin Carcinogenesis in Mice. ECAM, 2005, 2 (1): 99-105.

28. Subramanian P, Harikrishnan B and Subash S. Effect of Withania Somnifera Root Powder on the Levels of Circulatory Lipid Peroxidation and Liver Marker Enzymes in Chronic Hyperammonemia. E-Journal of Chemistry, October 2008; Vol. 5(4): pp. 872-877.

29. Thirumalai T, Viviyan, Therasa S, Elumalai EK, David E, Hypolipidaemic and antioxidant effect of Enicostemma littorale Blume. Asian Pacific Journal of Tropical Biomedicine, 2011; 381-385. 


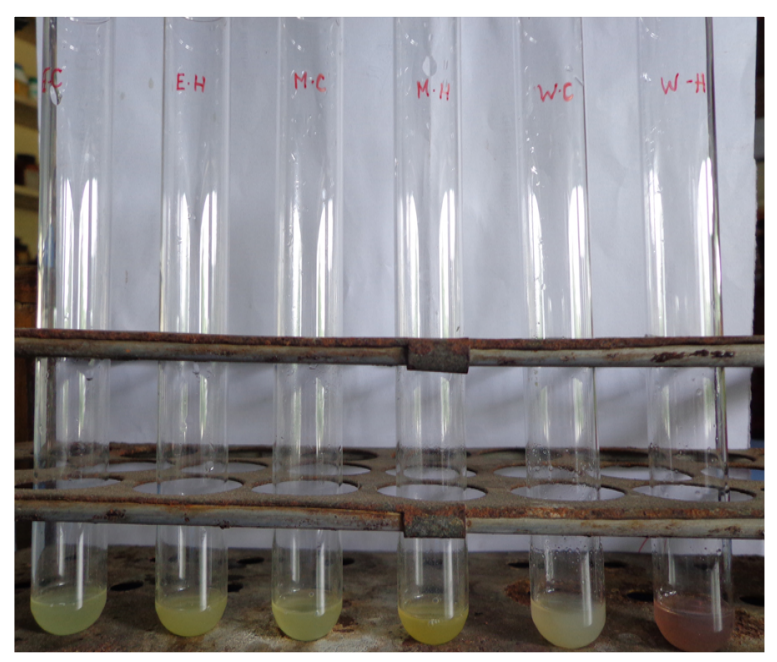

Alkaloids in Withania

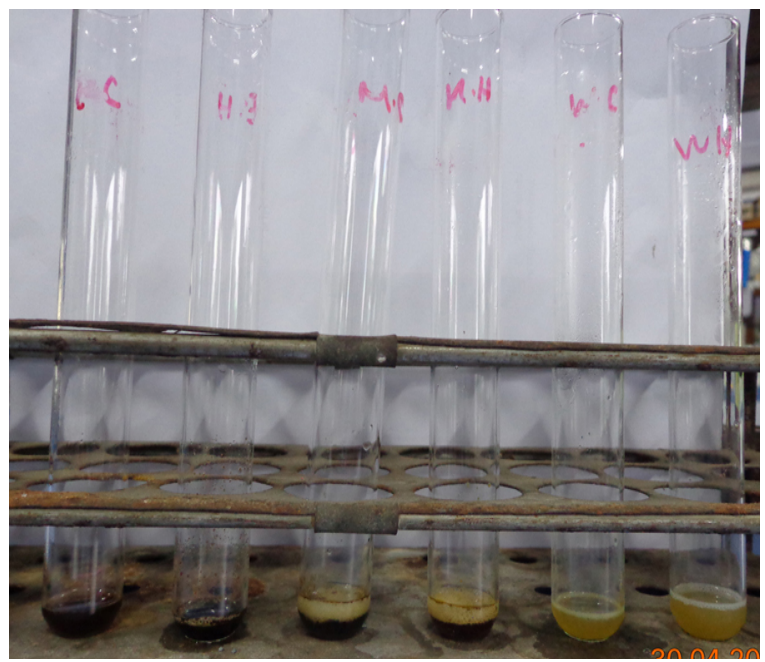

Flavonoids in W. somnifera

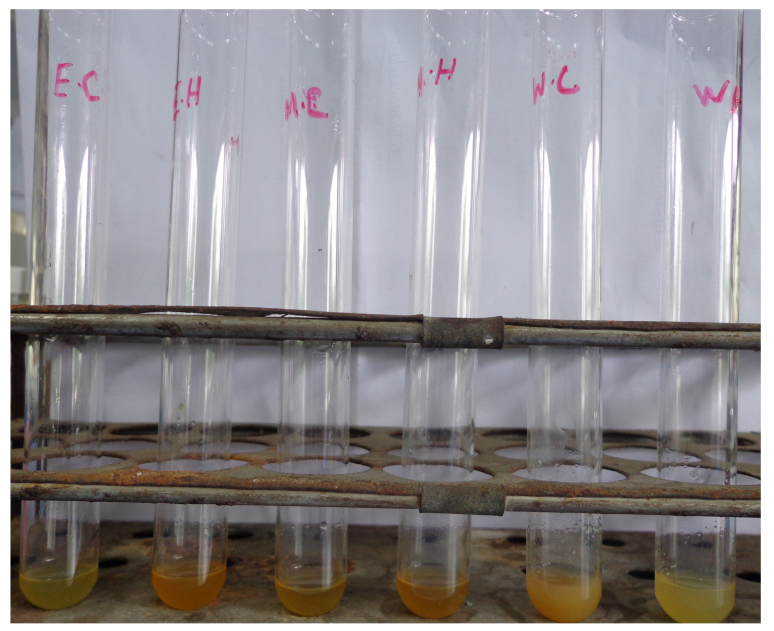

Proteins in W. somnifera

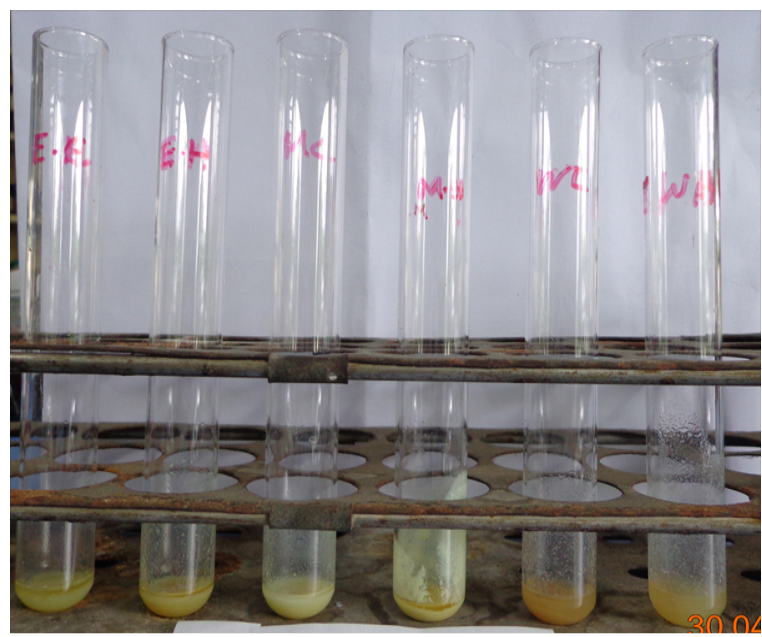

Coumarins in W. somnifera

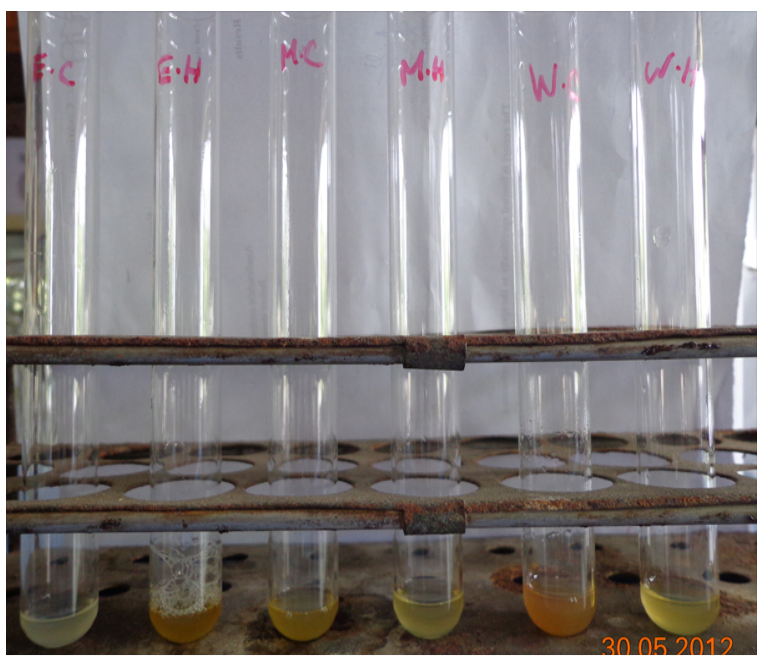

Anthraquinones in $W$.

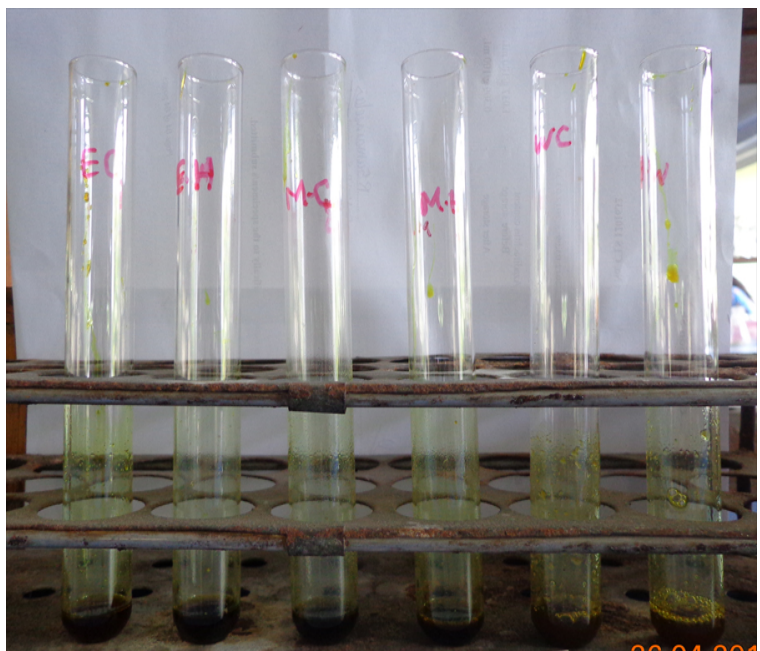

Phenolics in $W$. somnifera 

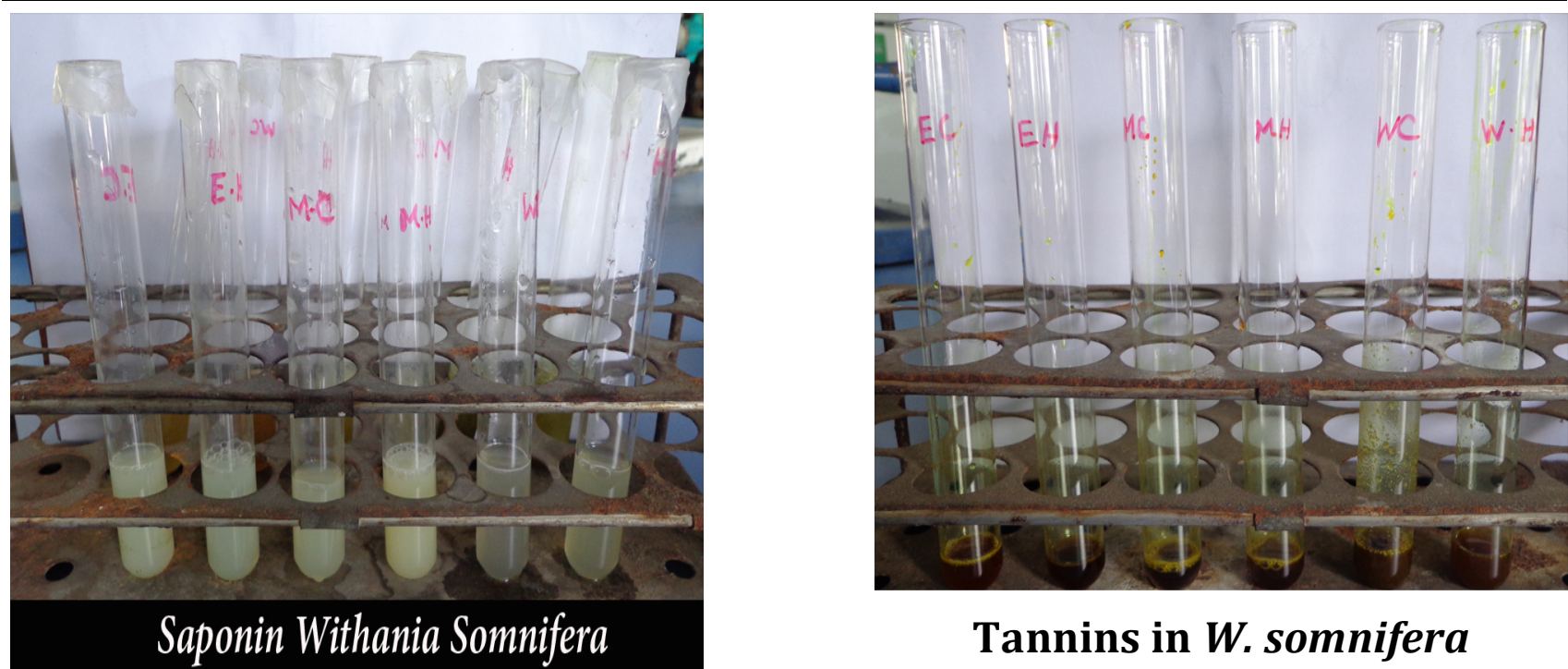

Tannins in W. somnifera

Saponins in Withania 